\title{
Adolescents' responses to cigarette advertisements: links between exposure, liking, and the appeal of smoking
}

\author{
Jeffrey Jensen Arnett, George Terhanian
}

\begin{abstract}
Objective-To evaluate adolescents' responses to cigarette advertisements for different brands.

Design-Adolescents were shown one print advertisement for each of five cigarette brands (Camel, Marlboro, Kool, Benson \& Hedges, and Lucky Strike). They indicated on a structured questionnaire how many times they had seen the advertisement (or one almost like it), how much they liked it, whether or not they thought it made smoking more appealing, and whether or not it made them want to smoke cigarettes of that brand.
\end{abstract}

Setting-Middle school and high school classrooms, seven schools in four states in the United States (New York, Pennsylvania, Ohio, and Texas). The classrooms were selected randomly within each school.

Participants-534 adolescents in grades 6-12 (ages 11-18 years) from seven schools in four states, $54 \%$ female, $76 \%$ white.

Results-The advertisements for Camel and Marlboro were more likely than the advertisements for the other brands to be seen, to be liked, to be viewed as making smoking appealing, and to influence adolescents to want to smoke cigarettes of that brand. More than $95 \%$ of the adolescents had seen an advertisement featuring Joe Camel or the Marlboro Man at least once, and more than $50 \%$ had seen these advertisements six or more times. Nearly half believed that the Joe Camel advertisement makes smoking more appealing, and $40 \%$ believed that the Marlboro Man advertisement makes smoking more appealing. Adolescent smokers were more likely than nonsmokers to believe that the advertisements for Camel and Marlboro make smoking more appealing.

Conclusions-The advertisements most popular among adolescents are for two of the brands they are most likely to smokeMarlboro and Camel. The results of the study are consistent with the view that certain cigarette advertisements enhance the appeal of smoking to many adolescents.

(Tobacco Control 1998;7:129-133)

Keywords: adolescents, advertising, brand preferences
Introduction

In the past decade, criticism of tobacco advertising has become especially intense. At the centre of the criticism is the assertion that tobacco advertising appeals to children and adolescents in a way that leads many of them to take up smoking as minors. The tobacco industry has long maintained that the aim of their advertising is to persuade adults to switch brands or to maintain their brand loyalty, and that the industry does not target its advertising to adolescents. ${ }^{1}$ However, studies indicate that $90 \%$ of adult smokers begin smoking by age $18,{ }^{2}$ and public health officials and advocates have charged that tobacco advertising is directed especially at adolescents, ${ }^{34}$ to draw them into the market and to establish an initial brand preference that they will maintain into adulthood. $^{5}$

Three factors have especially contributed to the growing criticism of tobacco advertising over the past decade. First, tobacco industry documents have been released in the course of litigation against the tobacco companies that provide evidence that tobacco advertising has been directed toward adolescents. The documents show a strong concern with the characteristics of adolescents that lead them to take up smoking, and describe research conducted to investigate these characteristics. Some of the documents make explicit references to minors. For example, a planning document for 1977-1986 produced by the RJ Reynolds Tobacco Company states, "Evidence is now available to indicate that the 14 to 18 year old group is an increasing segment of the smoking population. RJR must soon establish a successful new brand in this market if our position in the Industry is to be maintained over the long term" (emphasis in the original).

A second reason for the growing criticism of tobacco advertising is the Joe Camel advertising campaign, which ran from 1988 to 1997. This campaign featured a cartoon camel, described in the advertisements as a "smooth character" and depicted typically in leisure situations such as playing cards with friends or presiding over a lively party of young people. Although RJR Nabisco (maker of Camel cigarettes) denies that the advertisement campaign was directed toward adolescents, there is substantial evidence that the campaign was most successful among those aged 12-17 years. Before the initiation of the campaign, the market share for Camel among underage smokers was virtually non-existent, less than 
$1 \%{ }^{3}$ However, 18 months after the Joe Camel advertisement campaign began, Camel's market share among 12-17 year olds had risen to $8 \%$, and by 1993 it had risen to more than $13 \%{ }^{7}$ The increase in market share that Camel attained among 12-17 year olds was greater than for any other age group. ${ }^{4}$ Furthermore, rates of adolescent smoking rose in the early $1990 \mathrm{~s},{ }^{8}$ and many public health advocates suggested that the Joe Camel campaign contributed to the increase. ${ }^{134}$ Studies have found that adolescents are more likely than adults to find Joe Camel advertisements "cool" and "interesting", ${ }^{3}$ and that even adolescent non-smokers name Joe Camel advertisements as their favourite cigarette advertisements. ${ }^{9} 10$ In response to growing criticism of the campaign, RJR Nabisco discontinued the Joe Camel theme in mid-1997.

The third reason for increased criticism of tobacco advertising is the growing research evidence of the role of advertising in smoking initiation among adolescents. Numerous important studies on this topic have appeared in the past decade. In one study, Pollay and colleagues traced tobacco companies' advertising expenditures in relation to rates of smoking among adolescents (aged 12-18) and adults over the period 1979-1993, and concluded that the effect of advertising on brand choice was three times as strong for adolescents as for adults. ${ }^{11}$ In another study, Pierce and colleagues examined trends in smoking initiation from 1944 to $1988 .^{12}$ They found that, for girls aged 14-17, a sharp rise in smoking initiation coincided with the introduction of three brands marketed to females-Virginia Slims, Silva Thins, and Eve-during 19671973. There was no such increase during this period for girls aged 18-20 or 10-13, nor for males. The advertisement campaigns were most effective among adolescent girls aged $14-17$, the age range when smoking initiation is most likely to take place.

We investigated adolescents' responses to cigarette advertisements for five different brands: Marlboro, Camel, Kool, Benson \& Hedges, and Lucky Strike. Marlboro was included because it has long held the dominant market share among minors and adults. Camel was included because of the evidence for the appeal of Joe Camel to young people. The other three brands were included because their current advertisement campaigns include themes that may be expected to appeal to young people. Like previous studies, we examined the degree of adolescents' self-reported exposure to cigarette advertisements, but for a wider range of brands than in most previous studies. Using a variety of brands allows for comparisons of how adolescents respond to advertisements for the most popular brands among adolescents, Marlboro and Camel, in contrast to less popular brands.

\section{Methods}

PARTICIPANTS

Adolescents in grades 6-12 (ages 11-18 years) participated in the study. The adolescents were from a convenience sample of seven schools in four states (New York, Pennsylvania, Ohio, and Texas). States and schools were chosen because the second author had done research in these schools previously and because the schools were believed to provide some degree of regional and ethnic diversity. Classrooms were chosen randomly within each school. Students were told that the study involved responses to cigarette advertisements and that their participation would be anonymous. All the students in class on the day of data collection participated in the study. There were 534 participants, including 121 in grades 6 and 7, 203 in grades 8 and 9, and 207 in grades $10-12$. There were 129 smokers $(24 \%)$ in the sample (who answered "yes" in response to the question, "Do you smoke cigarettes?"). Fifty-four per cent of the participants were female; $76 \%$ were white, $6 \%$ black, $9 \%$ Hispanic, 3\% Asian, and $6 \%$ other.

\section{MATERIALS}

Participants were shown one print advertisement (in colour) for each of the five brands. The Marlboro advertisement depicted the "Marlboro Man" taking a cigarette out of a pack of Marlboros. The Camel advertisement depicted Joe Camel flipping a chip of the kind used as a gambling token. The Kool advertisement depicted three people skiing down a mountain slope. The Benson \& Hedges advertisement depicted a party on the roof of a building. The Lucky Strike advertisement depicted a young man standing on a street next to a motorcycle. For all advertisements, the brand name of the cigarette was not concealed or disguised; rather, the advertisement was shown as it appeared in print.

On a structured questionnaire, participants indicated for each advertisement how many times they had seen it (never, once or twice, three to six times, or more than six times); how much they liked the advertisement (like very much, somewhat like, somewhat dislike, dislike very much); whether or not they thought the advertisement makes smoking more appealing (yes/no); and whether or not the advertisement made them want to smoke cigarettes of that brand (yes/no). For the two brands that use the same character in a variety of advertisementsJoe Camel and the Marlboro Manparticipants were asked whether or not they recognised the character. Participants were also asked whether or not they smoked (yes/no). Demographic questions were included as part of the questionnaire.

\section{PROCEDURE}

The adolescents were shown pictures of the advertisements as they had appeared, although without the magazine context. Different groups of students were shown the advertisements in rotating order, so that the order of presentation varied. The students completed the questionnaire portion for each advertisement following its presentation.

The study was conducted during January 1997. 


\section{Results}

The demographic characteristics of the sample are described above. The frequencies regarding exposure and responses to the advertisements appear in table 1 .

As table 1 shows, most of the adolescents had seen the advertisements for Camel, Marlboro, and Kool more than six times. The highest level of exposure was for the Camel advertisement, followed by Marlboro, Kool, Benson \& Hedges, and Lucky Strike. Furthermore, $98 \%$ of the adolescents indicated that they recognised the Joe Camel character and 92\% recognised the Marlboro Man. Most of the adolescents had never seen the advertisements for Benson \& Hedges (65\% never) or Lucky Strike ( $75 \%$ never).

The degree of adolescents' exposure to the advertisements was related to the degree to which they liked ("like very much" or "somewhat like") the advertisements (table 1). The advertisement liked by the greatest proportion of adolescents was for Camel, followed by Marlboro, Kool, Benson \& Hedges, and Lucky Strike.

Table 1 Exposure and responses to cigarette advertisements, smokers and non-smokers

\begin{tabular}{|c|c|c|c|c|c|c|c|c|c|c|c|c|}
\hline & \multicolumn{3}{|c|}{$\begin{array}{l}\text { Seen (>6 times) } \\
(\%)\end{array}$} & \multicolumn{3}{|c|}{$\begin{array}{l}\text { Like } \\
(\%)\end{array}$} & \multicolumn{3}{|c|}{$\begin{array}{l}\text { Appealing } \\
(\%)\end{array}$} & \multicolumn{3}{|c|}{$\begin{array}{l}\text { Want } \\
(\%)\end{array}$} \\
\hline & All & $S$ & NS & All & $S$ & $N S$ & All & $S$ & $N S$ & All & $S$ & $N S$ \\
\hline Marlboro & 63 & 75 & 60 & 44 & 74 & 35 & 40 & 53 & 37 & 22 & 61 & 9 \\
\hline Camel & 76 & 78 & 75 & 64 & 88 & 57 & 49 & 61 & 45 & 17 & 43 & 8 \\
\hline Kool & 56 & 56 & 56 & 38 & 52 & 33 & 30 & 35 & 29 & 9 & 28 & 3 \\
\hline Benson \& Hedges & 6 & 10 & 5 & 26 & 41 & 22 & 21 & 18 & 22 & 6 & 13 & 3 \\
\hline Lucky Strike & 3 & 5 & 3 & 26 & 38 & 22 & 24 & 26 & 24 & 6 & 14 & 3 \\
\hline
\end{tabular}

$S=$ smokers $(n=129), N S=$ non-smokers $(n=403)$.

The figures for "Like" combine the responses of "Like very much" and "Somewhat like".

Table 2 Regression analyses, Exposure and Liking

\begin{tabular}{lcccll}
\hline & Grade & Gender & Ethnicity & $\begin{array}{l}\text { Smokers/ } \\
\text { non-smokers }\end{array}$ & $R^{2}$ \\
\hline Exposure & & & & & \\
$\quad$ Marlboro & $0.13^{\star \star}$ & $-0.08^{\star}$ & $-0.11^{\star \star}$ & $-0.10^{\star}$ & $0.05^{\star \star \star}$ \\
Camel & 0.06 & 0.08 & -0.01 & -0.02 & 0.01 \\
Kool & $0.09^{\star}$ & $0.17^{\star \star \star}$ & 0.04 & -0.02 & $0.04^{\star \star \star}$ \\
Benson \& Hedges & $0.10^{\star}$ & 0.03 & 0.03 & -0.08 & $0.02^{\star}$ \\
Lucky Strike & $0.10^{\star}$ & -0.07 & -0.05 & -0.05 & $0.02^{\star}$ \\
Liking & & & & & $0.011^{\star \star \star}$ \\
Marlboro & $0.13^{\star \star}$ & $0.10^{\star \star}$ & $0.09^{\star}$ & $0.20^{\star \star \star}$ \\
Camel & 0.05 & $0.09^{\star}$ & -0.01 & $0.38^{\star \star \star}$ & $0.15^{\star \star \star}$ \\
Kool & 0.05 & -0.01 & -0.08 & $0.19^{\star \star \star}$ & $0.04^{\star \star \star}$ \\
Benson \& Hedges & -0.02 & -0.08 & -0.01 & $0.17^{\star \star \star}$ & $0.04^{\star \star \star}$ \\
Lucky Strike & -0.04 & 0.06 & 0.07 & $0.14^{\star \star}$ & $0.03^{\star \star}$ \\
\hline
\end{tabular}

${ }^{\star} \mathrm{p}<0.05 ;{ }^{\star \star} \mathrm{p}<0.01 ;{ }^{\star \star \star} \mathrm{p}<<0.001$.

The numbers shown (except for the far right column) are the beta weights.

Table 3 Logistic regression analyses, Appealing and Want to smoke

\begin{tabular}{lllll}
\hline & Grade & Gender & Ethnicity & $\begin{array}{c}\text { Smokers/ } \\
\text { non-smokers }\end{array}$ \\
\hline Appealing & $1.14^{\star \star}$ & 1.05 & 1.15 & $2.14^{\star \star \star}$ \\
$\quad$ Marlboro & $1.21^{\star \star \star}$ & 0.86 & 1.02 & $2.16^{\star \star \star}$ \\
Camel & $1.20^{\star \star \star}$ & $0.56^{\star \star}$ & 1.13 & 1.54 \\
Kool & $1.18^{\star \star}$ & 0.69 & 0.96 & 0.87 \\
Benson \& Hedges & $1.20^{\star \star}$ & 0.92 & 0.87 & 1.18 \\
Lucky Strike & $1.23^{\star \star}$ & 1.28 & 1.21 & $20.48^{\star \star \star}$ \\
Want to Smoke & $1.29^{\star \star \star}$ & 1.44 & 1.06 & $10.43^{\star \star \star}$ \\
Marlboro & $1.66^{\star \star \star}$ & 0.85 & 1.11 & $19.66^{\star \star \star}$ \\
Camel & $1.46^{\star \star}$ & 1.48 & 0.78 & $5.79^{\star \star \star}$ \\
Kool & $1.46^{\star \star}$ & 2.07 & $0.68^{\star}$ & $6.75^{\star \star \star}$ \\
Benson \& Hedges & Lucky Strike & & & \\
\hline p & & & & \\
\hline
\end{tabular}

${ }^{\star} \mathrm{p}<0.05 ;{ }^{\star \star} \mathrm{p}<0.01 ;{ }^{\star \star \star} \mathrm{p}<0.001$.

The numbers shown are odds ratios.
The Camel and Marlboro advertisements were also the ones that were most likely to be viewed by the adolescents as making smoking more appealing (table 1). The rank order was similar to the responses for exposure and liking, with the advertisement for Camel having the highest appeal rating, followed by those for Marlboro, Kool, Lucky Strike, and Benson \& Hedges. A similar rank order was found for responses to the question of whether or not an advertisement made them want to smoke cigarettes of that brand, but with Marlboro highest, followed by Camel, Kool, and the other two brands.

Analyses were conducted concerning the relations between the advertisement variables and smoking status, with grade, gender, and ethnicity as covariates. Because ethnic differences in brand preferences have revealed patterns distinctive to African Americans but not other ethnic groups, ${ }^{2}$ ethnicity was analysed as a dichotomous variable comparing African Americans $(n=33)$ to all other adolescents. Regression analyses were conducted for Exposure and Liking. Because the dependent variables for some brands violated the assumption of a normal distribution that is made in regression analyses, the logs of the Exposure and Liking variables were used as the dependent variables. Logistic regression analyses were conducted for the Appealing and Want to Smoke variables because these variables were dichotomous. For the regression analyses as well as for the logistic regression analyses, smoking status and the covariates were entered simultaneously into the equations.

The results of these analyses are shown in tables 2 and 3. With respect to Exposure, smokers reported higher exposure to advertisements for Marlboro but not the other brands. Older adolescents reported more exposure to advertisements for all brands except Camel. With respect to Liking, smokers expressed higher liking than non-smokers for the advertisements of all five brands.

With respect to their perceived appeal (table 3), for the Marlboro and Camel advertisements, smokers were more likely than non-smokers to believe that the advertisements make smoking more appealing. For all five advertisements, older adolescents were more likely than younger adolescents to believe that they make smoking more appealing. With respect to whether the advertisements made them want to smoke that brand, smokers were more likely than non-smokers to respond affirmatively to this question, for all five brands. Similarly, older adolescents were more likely than younger adolescents to respond affirmatively to this question, for all five brands.

\section{Discussion}

Our data support the concerns expressed by public health advocates over the Joe Camel and Marlboro Man advertising campaigns. The advertisements for these brands are the ones that adolescents have seen most, like the best, and believe are most likely to make smoking more appealing. Adolescents who smoke are 
especially prone to like them and to believe they make smoking more appealing.

It is worth noting that adolescents' reported exposure to the advertisements corresponds roughly, but not exactly, to tobacco companies' advertising budgets for each brand. In the first ten months of 1996, the rank order of advertising budgets for the brands included here were as follows ${ }^{13}$ : Marlboro ( $\$ 84$ million), Camel ( $\$ 40$ million), Kool (\$36.5 million), Benson \& Hedges (\$12.6), and Lucky Strike (\$882 000). This rank order generally corresponds to adolescents' responses of how much they had seen the advertisements, as well as how much they liked them, whether or not they found the them appealing, and whether or not they made them want to smoke a cigarette of that brand. However, the notable exception is for the Joe Camel advertisement. Although less than half as much money was spent in the first 10 months of 1996 on the Joe Camel campaign as on advertisements featuring the Marlboro Man, Joe Camel advertisements were reported by adolescents in our study to have been seen most often (perhaps indicating that they were more likely than Marlboro advertisements to be noticed by adolescents), and were also the advertisements most liked and most likely to be seen as making smoking appealing. This indicates that the Joe Camel campaign was uniquely effective in its appeal to adolescents.

Much of the criticism of the Joe Camel advertising campaign has been based on findings of high rates of recognition of the Joe Camel character among young children. In a study that took place shortly after the Joe Camel campaign began, a high proportion of children aged 3-6 years matched Joe Camel with cigarettes, with the proportion rising with age to $91 \%$ of the six year olds. ${ }^{14}$ The authors of the study concluded that recognition of the brand in childhood may translate to use of the product later in life. However, two other studies, although similarly finding high rates of recognition of the Joe Camel character among young children, also found that the children's attitudes toward cigarettes were overwhelmingly negative..$^{15}{ }^{16}$ The authors of these two studies concluded that, in the light of the negative views of cigarettes held by children, high exposure to advertisements featuring Joe Camel may make them less likely to smoke cigarettes years later, because the exposure would only intensify their negative sentiments toward cigarettes.

Our data support quite a different conclusion. The adolescents in our study (which took place in January 1997) would have been exposed to the Joe Camel advertising campaign (which began in 1988) for nearly 10 years. Virtually all of them reported that they had seen a Joe Camel advertisement at least once, and more than three-quarters reported seeing them at least six times. Yet their attitudes toward the advertisements were far from negative, and a substantial proportion viewed the advertisements as making smoking more (not less) attractive. Two-thirds indicated that they liked the advertisements, and nearly half indicated that they make smoking more appealing. A similar pattern was found for
Marlboro advertisements- - high exposure along with a high level of liking and a substantial proportion who believed they make smoking more appealing. Furthermore, adolescent smokers were even more likely than non-smokers to like the advertisements and to believe they make smoking more appealing. ${ }^{3} 8$

Our findings are consistent with the view that cigarette advertising plays a role in making smoking attractive to adolescents. The advertisements the adolescents have seen the most often are also the ones they like the most and are for the brands they are most likely to smoke. Advertisers have long relied on the power of what is known as "mere exposure", the psychological principle that repeated exposure to a stimulus leads to favourable attitudes toward it-familiarity leads to liking, in other words. ${ }^{17}$ This principle has been verified in numerous social psychology studies, and these studies have found that it applies to children as well as adults. ${ }^{18}{ }^{19}$ Although studies also find that, for children, the preferences of parents can override the effects of mere exposure, ${ }^{20}$ it could be expected that for adolescents, who are in the process of becoming more independent from parental influences, the principle of mere exposure would assert itself more strongly than for children. Mere exposure may, in fact, be stronger for adolescents than for adults as well-research by Pollay et al has found that the relationship between cigarette advertising expenditures and cigarette brand choice is three times stronger for adolescents than for adults. ${ }^{11}$

Research on advertising has also established that exposure to advertisements leads not only to favourable attitudes toward the brand being advertised (for example, Camel) but also toward the product (cigarettes) more generally, ${ }^{21}$ and that this favourable attitude leads to intention to buy the product and to actual purchase of the product. ${ }^{22}$ However, recent research in this area has stressed that affect (emotion) is a critical link between exposure and purchase..$^{22}$ Memory alone is not enough; the memory must also be associated with a favourable affect toward the product. It is evident from our results that the Joe Camel and Marlboro Man campaigns have succeeded in promoting not only a widespread awareness of these advertisements among adolescents but also a positive affect toward these brands and toward smoking, as indicated in the findings that most adolescents like the advertisements and nearly half believe that they make smoking more appealing.

Furthermore, it is of considerable interest that adolescent smokers like the Joe Camel and Marlboro Man advertisements even more than adolescent non-smokers, and are more likely than non-smokers to believe that they make smoking more appealing. ${ }^{23}$ This may indicate that the advertisements for these brands promote smoking among adolescents. It is notable that as adolescents move beyond grades 6-7 and into the period of highest risk for smoking initiation, grades $8-12$, they are more likely to rate the advertisements as making smoking 
more appealing and as making them want to smoke cigarettes of the advertised brand.

Another possible interpretation of the results regarding smoking status and responses to the advertisements is that adolescent smokers view the advertisements more favorably because they naturally have an interest in advertisements for a product they already use. However, previous research indicates that even among adolescents who are non-smokers, the non-smokers who are most at-risk for smoking initiation also tend to be the most receptive to tobacco advertising. ${ }^{9}$ It is also notable that, although smokers are more likely than non-smokers to agree that certain advertisements make smoking more appealing, this applies not to all advertisements but only to those for Marlboro and Camel, two of the brands that adolescents are currently most likely to smoke. This may indicate that smokers respond more strongly to the Marlboro and Camel advertisements, not simply because these advertisements make them think of cigarettes generally, but because they strike a resonant chord in their developmental needs as adolescents and in their individual personalities. It may be that the capacity of the advertisements to strike those chords in them was one of the factors that led to smoking initiation for them but not for their non-smoking peers.

The study contains limitations that should be noted. Schools were chosen for data collection not randomly but as a convenience sample on the basis of contacts from previous research by the second author. Our sample of adolescents was clustered within these schools, which is less desirable than sampling randomly from many more schools, because the clustering may magnify any characteristics specific to a particular school. Also, in retrospect it would have been preferable to collect information on cigarette brands smoked by the smokers in the sample, to relate their brand preference to their brand-specific responses. Furthermore, the study was cross-sectional rather than longitudinal; this limits the extent to which conclusions about causality can be drawn.

The 1994 report on youth smoking by the Institute of Medicine observed, "The question is not, are advertising and promotion the causes of youth initiation, but rather, does the preponderance of evidence suggest that features of advertising and promotion tend to encourage youths to smoke?" 24 It is increasingly evident that the answer to this question is yes. The implication of this answer should be no less evident: in the interest of reducing smoking among adolescents, cigarette advertising and promotion should be banned or restricted to adults-only venues.

The views and conclusions expressed are those of the authors and do not necessarily represent those of the Gordon S Black Corporation, for whom GT is a project manager.

1 Gostin LO, Arno PS, Brandt AM. FDA regulation of tobacco advertising and youth smoking: historical, social, and constitutional perspectives. FAMA 1997;277:410418

2 US Department of Health and Human Services. Preventing tobacco use among young people. A report of the Surgeon General, 1994. Atlanta, Georgia: Public Health Service, Centers for Disease Control and Prevention, Office on Smoking and Health, 1994. (US Government Printing Office No S/N 017-001-00491-0.)

3 DiFranza JR, Richards JW, Paulman PM, et al. RJR Nabisco's cartoon camel promotes Camel cigarettes to children. fAMA 1991;266:3149-53.

4 Pierce JP, Gilpin E, Burn DM, et al. Does tobacco advertising target young people to start smoking? Evidence from ing target young people to start smoking?
California. $₹ A M A 1991 ; 266: 3154 ; 3158$

5 DiFranza JR, Eddy JJ, Brown LF, et al. Tobacco acquisition and cigarette brand selection among youth. Tobacco Control 1994;3:334-8.

6 Hilts PJ. Smokescreen: the truth behind the tobacco industry cover-up. New York: Addison-Wesley, 1996.

7 US Center for Disease Control and Prevention. Changes in the cigarette brand preferences of adolescent smokersUnited States, 1989-1993. MMWR 1994;43:577-81.

8 Cigarette smoking continues to rise among American teenagers in 1996. Unpublished news release, Monitoring the Future Study, University of Michigan News and Information Services, Ann Arbor, Michigan, USA.

9 Evans N, Farkas A, Gilpin E, et al. Influence of tobacco marketing and exposure to smokers on adolescent suscep-

10 Huang PP, Burton D, Howe HL, et al. Black-white differences in appeal of cigarette advertisements among differences in appeal of cigarette advertise.

11 Pollay RW, Siddarth S, Siegel M, et al. The last straw? Cigarette advertising and realized market shares among youth rette advertising and realized market shares among

12 Pierce JP, Lee L, Gilpin EA. Smoking initiation by adolescent girls, 1944 through 1988: an association with targeted advertising. $\mathscr{f} A M A$ 1994;271:608-11.

13 Wells $M$. Kids know Joe Camel, but they follow Marlboro Man. USA Today 1997 Jan 31:5B.

14 Fischer PM, Schwarz MP, Richards JW Jr, et al. Brand logo recognition by children aged 3 to 6 years; Mickey Mouse and Old Joe the Camel. FAMA 1991;266:3145-8.

15 Henke L. Young children's perceptions of cigarette brand advertising symbols: awareness, affect, and target market identification. F Advertising 1995;24:13-28.

16 Mizerski R. The relationship between cartoon trade character recognition and attitude toward product category in young children. $₹$ Marketing 1995;59:58-70.

17 Zajonc R. Attitudinal effects of mere exposure. F Personality Soc Psychol Monogr 1968;9:1-27.

18 Raju PS, Subhash CL. Advertising to children: findings and implications. In: Leigh J, Martin C, eds. Current issues and research in advertising, vol. 12. Ann Arbor, Michigan: University of Michigan, 1989:231-74.

19 Bornstein R. Exposure and affect: overview and metaanalysis of research, 1968-1987. Psych Bull 1989;106:26589

20 Goldberg ME, Gorn GJ. Some unintended consequences of TV advertising to children. $\mathcal{F}$ Consumer Res 1978;5:22-9.

21 Goldberg ME, Gorn GJ, Gibson W. TV messages for snack and breakfast foods: do they influence children's preferences? F Consumer Res 1978;5:73-81.

22 Thorson E. Consumer processing of advertising. In: Leigh J, Martin C, eds. Current issues and research in advertising, vol. 12. Ann Arbor, Michigan: University of Michigan, 1989:197-230.

23 Peters J, Betson CL, Hedley AJ, et al. Recognition of cigarette brand names and logos by young children in cigarette brand names and logos by young

24 Lynch BS, Bonnie RI, eds. Growing up tobacco free: preventing nicotine addiction in children and youths. Washington, DC: Institute of Medicine, National Academy Press, 1994. 